\title{
Concurrent Solvent Induced Crystallization and \\ Hydrolytic Degradation of PLA by Water-Ethanol
}

\section{Solutions}

Fabiola Iñiguez-Franco ${ }^{a}$, Rafael Auras ${ }^{a, *}$, Gary Burgess ${ }^{a}$, Daniel Holmes $^{b}$, Xiaoyi

Fang $^{\text {a,d }}$, Maria Rubino ${ }^{a}$, Herlinda Soto-Valdez ${ }^{c}$

${ }^{\text {a }}$ School of Packaging, ${ }^{\mathrm{b}}$ Chemistry Department, Michigan State University, East

Lansing, MI, 48824-1223, United States.

${ }^{c}$ Centro de Investigación en Alimentación y Desarrollo, A.C., Apdo. Postal 1735,

Hermosillo, Sonora 83304, México.

${ }^{d}$ Saint Gobain Performance Plastics, Aurora, OH, 44202-8001, United States.

*Corresponding author: aurasraf@msu.edu

Keywords: Hydrolysis, swelling, poly(lactic acid) 


\section{ABSTRACT}

Poly(lactic acid) (PLA) films were immersed in pure water, 50\% and $95 \%$ ethanol solutions for up to 180 days. The change in molecular weight, sorption of water, sorption of ethanol, and lactic acid released were monitored. Glass transition temperature and percent crystallinity as a function of ethanol content were also measured. PLA experienced faster hydrolytic degradation in contact with $50 \%$ than with $95 \%$ ethanol or pure water. NMR methodologies were developed to measure sorption of deuterated water and ethanol in PLA. More water was sorbed in $50 \%$ ethanol, explaining the higher hydrolysis. During exposure, PLA experienced solvent induced crystallization. Higher percent crystallinity was found in films exposed to $50 \%$ ethanol with the formation of a-form crystals. The hydrolysis of PLA was correlated with the release of lactic acid during exposure. Mathematical models are proposed to explain the concurrent solvent induced crystallization and hydrolytic degradation of PLA. 


\section{INTRODUCTION}

Poly(lactic acid) (PLA) is one of the most widely used biopolymers. It has gained attention in recent years as a promising alternative to polymers from nonrenewable resources. PLA is a linear aliphatic thermoplastic polyester, in which lactic acid (LA) is the precursor, obtained from the fermentation of corn sugar [1]. Currently, the world capacity for production of PLA is 150,000 metric tons [2]. The versatility of PLA has led to broad and diverse applications. In the medical field, due to its biocompatibility with the human body, PLA has been used for applications such as sutures, stents and drug delivery systems.[3-6] In agriculture, PLA has been used as a material for the controlled release of herbicides [7-9] or as a plastic to protect soil and plants from erosion, insects and birds [10]. In packaging, PLA has been used as both a film and a rigid thermoform for containers for food and non-food products [1, 11-13].

Depending on the application, PLA can be exposed to different kinds of media, including water and/or ethanol. In the medical field, it can be in contact with aqueous systems or biological media for drug delivery systems [14-16]. For example, disinfection of electrospun materials for tissue engineering is commonly carried out by ethanol soaking [17-19]. In agriculture, for growth stimulation and the controlled release of pesticides, PLA is in a high relative humidity environment or in direct contact with water [7, 20]. In packaging applications, when PLA is used for beverage and fresh food containers, it could be in direct contact with water or ethanol, or be exposed to humid environments. These 
types of exposure to various environmental conditions could favor PLA degradation.

PLA degradation leads to changes in mechanical and thermal properties, molecular weight and morphology [21-24]. PLA in the presence of water is susceptible to hydrolytic degradation. The ester groups are hydrolytically degraded, leading to a decrease in molecular weight and the release of low molecular weight soluble oligomers and monomers [1, 25]. Conversely, it has been found that PLA will plasticize and crystallize in the presence of organic solvents, which swell the polymer matrix, increasing chain mobility and inducing solvent induced crystallization (SIC) [23, 26-28]. The SIC behavior has been studied in polymers such as poly(methyl methacrylate) [29], poly(carbonate of bisphenol A) [30], polystyrene [31-33], and poly(ethylene terephthalate) [34-36], SIC is a complex phenomenon involving many processes, such as diffusion of solvent molecules, swelling, plasticization and crystallization. Several factors can affect each process involved in SIC. Examples are initial crystallinity, temperature, molecular weight and solvent chemistry [30-36]. In a study of SIC in PLA ultrathin films, Wu et al. found that in the initial diffusion stage, the solvent molecules interact with random PLA coil chains, which increase the motion of the PLA segments [28]. These interactions can lead to either dissolution of the polymer or nucleation, leading to the rearrangement of PLA chains into crystal lattices. Therefore, understanding the concurrent effect of SIC and hydrolytic degradation of the PLA matrix as it is exposed to water-ethanol solutions is of paramount 
importance to fully control and/or develop its applications and tailor its uses, which was the goal of this work.

\section{MATERIALS AND METHODS}

\section{Chemicals and Reagents}

PLA resin (3.8-4.2\% D-LA) was obtained from NatureWorks LLC (Minnetonka, MN, USA) with a weight and number average molecular weight $\left(M_{w}, M_{n}\right)$ of 2.35 $\pm 0.07 \times 10^{5} \mathrm{Da}$ and $1.21 \pm 0.08 \times 10^{5} \mathrm{Da}$, respectively. Ethanol (HPLC grade), acetonitrile (HPLC grade), methanol (HPLC grade), and formic acid were supplied by Sigma-Aldrich (St. Louis, MO, USA), tetrahydrofuran (THF) by Pharmco-AAPER (North East, CA, USA), and water (HPLC grade) by J.T. Baker (Center Valley, PA, USA). L(+) LA was purchased from Supelco (Bellefonte, PA, USA). Malonic acid was obtained from Columbus Chemical Industries (Columbus, WI, USA). Deuterium oxide (D, 99.9\%) $\left(\mathrm{D}_{2} \mathrm{O}\right)$ and chloroform-D (D, 99.8\%) $\left(\mathrm{CDCl}_{3}\right)$ were purchased from Cambridge Isotope Laboratories (Andover, MA, USA). N,N-Dimethylformamide (DMF) was provided by Avantor Performance Materials (Center Valley, PA, USA). Water used in the HPLC mobile phase was purified using Milli-Q System from Millipore Corp (Bedford, MA, USA).

\section{Production of PLA film}


PLA pellets were dried at $60^{\circ} \mathrm{C}$ for $24 \mathrm{~h}$ under vacuum ( $85 \mathrm{kPa}$ ) and processed in a Randcastle cast film microextruder (Extrusion System, Inc., Cedar Grove, NJ, USA) with a screw of $1.5875 \mathrm{~cm}$ diameter, 24/1 L/D ratio extruder, and $34 \mathrm{cc}$ volume. Extrusion temperatures were $193,212,215,215$ and $210{ }^{\circ} \mathrm{C}$ for zone 1 , 2 , and 3 transfer tube and die, respectively, with a rotation speed of $60 \mathrm{rpm}$. The film thickness was $27.9 \pm 9.9 \mu \mathrm{m}$.

\section{Storage experiments}

Ten disks $2.0 \mathrm{~cm}$ in diameter separated by glass beads on a stainless steel wire were placed in cells containing pure water, $50 \%$ ethanol, or $95 \%$ ethanol by volume, previously conditioned at $40^{\circ} \mathrm{C}$. The total disk surface area to fluid volume was $1.79 \mathrm{~cm}^{2} / \mathrm{mL}$. Degradation and release experiments were conducted at $40^{\circ} \mathrm{C}$ using a migration cell as recommended by ASTM D4754-11 [37]. Samples were retrieved at defined times during 6 months to assess $M_{w}, M_{n}$, water and ethanol sorption, thermal and physical properties, and LA release.

\section{PLA molecular weight}

At various times throughout the experiments, $M_{w}$ and $M_{n}$ were determined by weighing approximately $10 \mathrm{mg}$ of film retrieved from the test cells and dissolved in THF (2 mg/mL). A gel permeation chromatograph (GPC) (Waters 1515, Waters, Milford, MA, USA) equipped with a refractive index detector (Waters 2414) and a series of three columns of HR Styragel® (HR4, HR3 and HR2) were 
used (each $7.8 \mathrm{~mm} \times 300 \mathrm{~mm}$, Waters Styragel). An elution of THF at a flow rate of $1 \mathrm{~mL} / \mathrm{min}$ was applied with a flow rate ramping time of $5 \mathrm{~min}$ and a total run time of $45 \mathrm{~min}$. The temperature of the detector and column was $35^{\circ} \mathrm{C}$ and the injection volume was $100 \mu \mathrm{L}$. A calibration curve was made from polystyrene standards-Shodex SM-105 (Waters, Milford, MA), which contained a molecular weight range of $1.37 \times 10^{3}$ to $2.48 \times 10^{6} \mathrm{Da}$. The Mark-Houwink constants for the correction were $K=0.0164 \mathrm{~mL} / \mathrm{g}$ and $\alpha=0.704$ for PLA solutions in THF at $35^{\circ} \mathrm{C}$. The measurements were conducted in triplicate.

\section{Water and ethanol sorption}

Water and ethanol sorbed by PLA film were measured at $40{ }^{\circ} \mathrm{C}$ using migration cells as described in the storage experiments section. In this study, the water $\left(\mathrm{H}_{2} \mathrm{O}\right)$ in the solvents (water, 50\% ethanol, 95\% ethanol) was replaced with $\mathrm{D}_{2} \mathrm{O}$ to avoid contamination from environmental water and interference with measurements. Ethanol sorbed was determined using the ${ }^{1} \mathrm{H}-\mathrm{NMR}$ (proton nuclear magnetic resonance) technique and water sorbed using D-NMR (Deuterium NMR). Samples of film were taken periodically. For ethanol sorption, the samples were rinsed with $\mathrm{D}_{2} \mathrm{O}$ and for water sorption with $\mathrm{H}_{2} \mathrm{O}$ to remove the solvent from the surface. For ethanol sorption, samples were dissolved in $\mathrm{CDCl}_{3}$ with DMF as the internal standard, and for water sorption, samples were dissolved in THF with $\mathrm{CDCl}_{3}$ as the internal standard. For ethanol and $\mathrm{D}_{2} \mathrm{O}$ sorption measurements, samples were analyzed using a Varian Inova $600 \mathrm{MHz}$ superconducting NMR-Spectrometer equipped with a Nalorac $5 \mathrm{~mm}$ PFG 
switchable probe operating at 599.892 $\mathrm{MHz}$ and $92.069 \mathrm{MHz}$ for ${ }^{1} \mathrm{H}$ and ${ }^{2} \mathrm{H}$, respectively. Experiments were conducted in triplicate. Detailed descriptions of the ${ }^{1} \mathrm{H}-\mathrm{NMR}$ and D-NMR experiments are provided in the Supporting Information available online.

Ethanol sorption appears to follow Fick's law of diffusion. The analytical solution with constant concentration assumed on both disk faces is [38]:

$$
\frac{M_{t}}{M_{\infty}}=1-\frac{8}{\pi^{2}} \sum_{n=0}^{\infty} \frac{1}{(2 n+1)^{2}} \exp \left(\frac{-D(2 n+1)^{2} \pi^{2} t}{l^{2}}\right)
$$

where $M_{t}$ is the amount of ethanol sorbed at time $t(\mathrm{~g}-\mathrm{EtOH} / \mathrm{g}-\mathrm{PLA}), M_{\infty}$ is the amount of ethanol at equilibrium ( $\mathrm{g}-\mathrm{EtOH} / \mathrm{g}-\mathrm{PLA}), t$ is time (s), $l$ is thickness of expanded disk $(\mathrm{m})$ and $D$ is the diffusion coefficient $\left(\mathrm{m}^{2} / \mathrm{s}\right)$. The nonlinear regression (nlin-fit) function in MATLAB® 2011b (MathWorks, Natick, MA) was used to fit Eq. 1. This provides an estimate of $M_{\infty}$ and $D$.

\section{Differential scanning calorimetry (DSC)}

A differential scanning calorimeter (Q100, TA Instruments New Castle, DE, USA) was used to determine the glass transition temperature $\left(T_{g}\right)$, melting temperature $\left(T_{m}\right)$, crystallization temperature $\left(T_{c}\right)$ and degree of crystallinity $\left(\% X_{c}\right)$ of the PLA samples. The samples where cooled from 25 to $5^{\circ} \mathrm{C}$ and then run at a temperature range of 5 to $210{ }^{\circ} \mathrm{C}$, with a heating rate of $10{ }^{\circ} \mathrm{C} / \mathrm{min}$ using liquid 
nitrogen with a flow rate of $70 \mathrm{~mL} / \mathrm{min}$. The first heat scans of the samples are reported. The data obtained were analyzed using the Thermal Analysis Universal 2000 version $4.5 \mathrm{~A}$ software. Percentage crystallinity was calculated using the heat of fusion of the $100 \%$ crystalline for PLA sample of $93.7 \mathrm{~J} / \mathrm{g}$ [39].

\section{X-ray diffraction study (XRD)}

XRD analyses were performed using a Bruker AXS D8 Advance X-ray

diffractometer (Bruker Co., Billerica, MA, USA) equipped with a Global Mirror filtered $\mathrm{Cu}$ Ka radiation source set at $40 \mathrm{kV}$ and $100 \mathrm{~mA}$. Samples were scanned in the $2 \theta$ range from $2^{\circ}$ to $40^{\circ}$ at a rate of $0.24 \% \mathrm{~min}$ and an increment of $0.01^{\circ}$.

\section{Dynamic mechanical analysis (DMA)}

To determine the $T_{g}$ of PLA, the loss factor (tan delta) was measured as a function of temperature when PLA samples were immersed between 4 and 7 days in the various ethanol-water solutions during testing. A TA RSA-G2 Solids Analyzer Immersion System (TA Instruments, New Castle, DE, USA) equipped with a tension geometry at a frequency of $1 \mathrm{~Hz}$ was used. The samples where cooled down from 25 to $10,-10,-10,-30$, and $-60{ }^{\circ} \mathrm{C}$ for $0,25,50,75$ and $95 \%$ ethanol volume and then heated to $60^{\circ} \mathrm{C}$ at a heating constant rate of $5{ }^{\circ} \mathrm{C} / \mathrm{min}$ using liquid nitrogen. The data obtained was analyzed using the TA Instruments TRIOS software. 


\section{Lactic acid release}

Release of LA into the three different solvent systems (water, $50 \%$ ethanol and $95 \%$ ethanol) was determined using the migration cell at $40{ }^{\circ} \mathrm{C}$ as described in the storage experimental section. Four replicates were performed for each of the solvent systems. LA quantification was carried out since lactide and oligomers are degradation products of PLA that are able to migrate and easily decompose to LA. Modified methods published by Mutsuga et al. and Di Maio et al. were used [40, 41]. Samples containing $0.5 \mathrm{~mL}$ of simulant were taken periodically and exposed to alkali hydrolysis. For ethanol solutions, the ethanol was evaporated using a Savant SC110 SpeedVac Concentrator System (Savant Instruments, Holbrook, NY, USA) and then reconstituted with $0.5 \mathrm{~mL}$ of water. Samples were then saponified with $50 \mu \mathrm{L}$ of $0.2 \mathrm{M}$ sodium hydroxide, followed by heating for 15 minutes in a water bath at $60{ }^{\circ} \mathrm{C}$. After cooling at room temperature, $50 \mu \mathrm{L}$ of 0.2 $M$ hydrochloric acid was added. LA was analyzed with an LC/MS/MS system with a triple quadrupole/linear ion trap (AB/Sciex QTRAP 3200, Framingham, MA, USA). Separation was carried out on an Ascentis Express C18, $2.7 \mu \mathrm{m}, 100 \times 2.1$ $\mathrm{mm}$ reverse phase column (Sigma-Aldrich, St. Louis, MO, USA.) with a flow rate of $0.2 \mathrm{~mL} / \mathrm{min}$. Solvents were A: $1 \%$ formic acid and B: methanol. Solvent programming was isocratic for 3 minutes with $1 \% \mathrm{~B}$, then a linear gradient to $95 \%$ B up to 2 minutes, followed by the isocratic mode for 2 minutes. A linear gradient was then carried out in 0.01 minutes to $1 \% \mathrm{~B}$ and held for 3 minutes in the isocratic mode. The oven temperature was $40^{\circ} \mathrm{C}$. Mass spectrometric analyses were performed in the negative-ion mode following the Ambient 
Pressure Chemical Ionization (APCI) method; the curtain gas was set to 20, gas-

120 and gas- 220 , with a temperature of $650^{\circ} \mathrm{C}$. The calibration curve was made from 0.25 to $15 \mu \mathrm{g} / \mathrm{mL}$ by treating the LA standard solutions in the same way as the samples and using malonic acid as the internal standard.

\section{RESULTS AND DISCUSSION}

To study the hydrolytic degradation and SIC of PLA by water-ethanol solutions, the change in molecular weight of PLA was analyzed during exposure to determine the rate of hydrolysis caused by the cleavage of the ester bonds. The sorption of water in PLA was studied since hydrolysis depends on the presence of water molecules in the polymer matrix. However, the ethanol molecules in the solvent solutions influenced the water sorption in PLA due to the swelling effect. Swelling studies were carried out and the initial first order reaction equation for $M_{n}$ reduction was modified to account the effect of PLA swelling in the rate constant. Crystallinity studies of PLA were performed over the exposure time to assess the concurrent SIC by ethanol molecules along with the hydrolysis of amorphous regions in the polymer matrix by water molecules. Finally, LA release was assessed as the result of the concurrent SIC and hydrolysis of the polymer chains and a model was proposed to predict the LA release when PLA is exposed to water-ethanol solutions.

\section{Molecular weight}


Figure 1 shows $M_{n}$ as a function of time for PLA disks immersed in water, 50\% ethanol and $95 \%$ ethanol at $40{ }^{\circ} \mathrm{C}$. Molecular weight decreased over time, indicating hydrolysis of PLA. However, the change in $M_{n}$ was different for PLA in the three solutions. A first order reaction relationship was fitted to the experimental data. Table 1 gives the rate constants $k\left(\mathrm{gmol}^{-1} \mathrm{~d}^{-1}\right)$ for each system. The $50 \%$ ethanol solution caused the highest rate of decrease of $M_{n}$ at 0.0223 gmol $^{-1} \mathrm{~d}^{-1}(p<0.05)$, followed by $95 \%$ ethanol and water at $0.0133(p<0.05)$ and $0.0059 \mathrm{gmol}^{-1} \mathrm{~d}^{-1}(\mathrm{p}<0.05)$, respectively. After 120 days, the films in $50 \%$ ethanol were no longer intact and dispersed as small fragments in the solvent. The reduction in $M_{n}$ during exposure is attributed to scission of the ester bond of the polymer chains by water molecules [22, 25]. Optical images of PLA samples immersed in the three different water-ethanol solutions during hydrolytic degradation are presented in Figure S3, Supporting Information. 


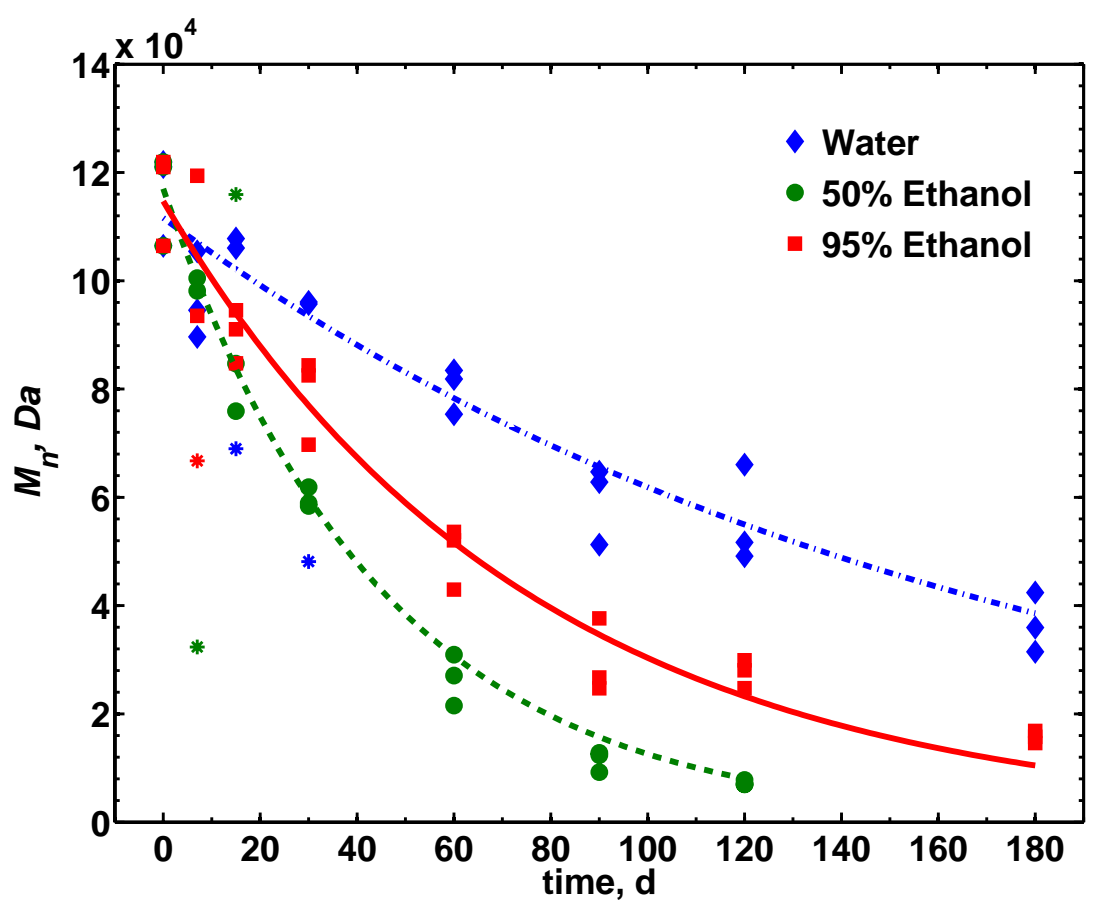

Figure 1. $M_{n}$ as a function of time during hydrolytic degradation of PLA film immersed in water, $50 \%$ ethanol and $95 \%$ ethanol at $40{ }^{\circ} \mathrm{C}$. Values indicated as * were considered outliers and therefore no used for fitting of the first order.

Table 1. Rate constants for PLA films at $40^{\circ} \mathrm{C}$ in water-ethanol solutions.

\begin{tabular}{cccc}
\hline & \multicolumn{3}{c}{$k\left(\mathrm{gmol}^{-1} \mathrm{~d}^{-1}\right)$ for $\boldsymbol{H}_{2} \mathrm{O}$ or $\boldsymbol{D}_{2}$ O/ethanol solutions } \\
\hline Solvent solution & $\boldsymbol{H}_{2} \boldsymbol{O}^{*}$ & $\boldsymbol{H}_{2} \boldsymbol{O}^{* *}$ & $\boldsymbol{D}_{2} \boldsymbol{O}^{* * *}$ \\
\hline Water & $0.0059 \pm 0.0004^{\mathrm{a}}$ & 0.0059 & $0.0020 \pm 0.0002^{\mathrm{a}}$ \\
$50 \%$ Ethanol & $0.0223 \pm 0.0010^{\mathrm{b}}$ & 0.0230 & $0.0124 \pm 0.0007^{\mathrm{b}}$ \\
95\% Ethanol & $0.0133 \pm 0.0004^{\mathrm{c}}$ & 0.0115 & $0.0111 \pm 0.0012^{\mathrm{b}}$ \\
\end{tabular}

${ }^{*}$ Fitting of first order reaction: $M_{n}=M_{n_{o}} \exp (-k t)$, where $M_{n}$ is the number average molecular weight at time $t$ and $M_{n_{o}}$ is the initial $M_{n}$. 
${ }^{* *}$ Fitting of first order reaction with $k$ from Eq. 2

*** Fitting of first order reaction kinetic. Synthetic data was used for calculations assuming a first order reaction since only the first and last points were measured. Values with different lower case letters in the same column are statistically different $(\alpha=0.05$ Tukey-Kramer Test)

Di Miao et al. and Sato et al. evaluated the effect of organic solvents like ethanol in contact with PLA, which swell the polymer matrix and increase chain mobility $[26,41]$. The creation of free volume due to swelling allows more water molecules to diffuse in and get sorbed in the PLA matrix. This accelerates the hydrolysis rate. A more complete understanding of the diffusion and sorption of water and ethanol during hydrolytic degradation should help to describe the mechanism of solvent assisted hydrolysis.

\section{Water and ethanol sorption}

Diffusion of $\mathrm{H}_{2} \mathrm{O}$ in PLA has been reported [42-44]. $D$ values of $3.53 \times 10^{-15} \mathrm{~m}^{2} / \mathrm{s}$ at $80 \%$ relative humidity $(\mathrm{RH})$ and $1.5 \times 10^{-11} \mathrm{~m}^{2} / \mathrm{s}$ at $90 \% \mathrm{RH}$ in vapor systems, and $2.92 \times 10^{-12} \mathrm{~m}^{2} / \mathrm{s}$ in immersion conditions were reported for PLA at $40{ }^{\circ} \mathrm{C}$. In our experiment, to simultaneously measure the rate of diffusion and sorption of water in PLA in ethanol solutions created technical challenges since the $\mathrm{H}_{2} \mathrm{O}$ peaks overlap with PLA resonances in the ${ }^{1} \mathrm{H}$-NMR spectrum as shown in the Supporting Information. Furthermore, excluding all extraneous sources of water from NMR measurements to ensure accurate measurements is extremely difficult. 
In contrast, $\mathrm{D}_{2} \mathrm{O}$ does not suffer the same issues and allows for the accurate measurement of sorption. Therefore, $\mathrm{D}_{2} \mathrm{O}$ water was used to simulate the diffusion of $\mathrm{H}_{2} \mathrm{O}$ in PLA. It is important to recognize that $\mathrm{D}_{2} \mathrm{O}$ will cause a different hydrolysis rate in PLA than $\mathrm{H}_{2} \mathrm{O}$ as is shown in Table 1, even though $\mathrm{D}_{2} \mathrm{O}$ and $\mathrm{H}_{2} \mathrm{O}$ may have the same initial diffusion coefficient as shown in Figure $\mathrm{S} 4$, Supporting Information, which shows the rate of diffusion of $\mathrm{H}_{2} \mathrm{O}$ vapor and $\mathrm{D}_{2} \mathrm{O}$ vapor in PLA. The $k$ values will decrease when $\mathrm{H}_{2} \mathrm{O}$ is replaced with $\mathrm{D}_{2} \mathrm{O}$ since hydrogen isotopes ${ }^{1} \mathrm{H}$ in $\mathrm{H}_{2} \mathrm{O}$ have been replaced by deuterium isotopes ${ }^{2} \mathrm{H}$, reducing the number of hydroxide (deuteroxide) ions that start the cleavage of the ester bonds.

Figure 2 shows the rate of $D_{2} \mathrm{O}$ sorption by PLA. The concentration of $\mathrm{D}_{2} \mathrm{O}$ molecules in PLA was lowest when the films were immersed in $\mathrm{D}_{2} \mathrm{O}$ and highest when immersed in $50 \%$ ethanol. The higher the concentration of $D_{2} \mathrm{O}$ in the PLA, the faster the hydrolysis by $\mathrm{D}_{2} \mathrm{O}$, since there are more molecules of $\mathrm{D}_{2} \mathrm{O}$ available to start the cleavage of ester bonds. However, faster cleavage should be expected if $\mathrm{H}_{2} \mathrm{O}$ were used due to the reactivity of hydroxyl groups, even though the sorption of $\mathrm{H}_{2} \mathrm{O}$ vapor and $\mathrm{D}_{2} \mathrm{O}$ vapor into PLA are similar (Figure S5, Supporting Information). 


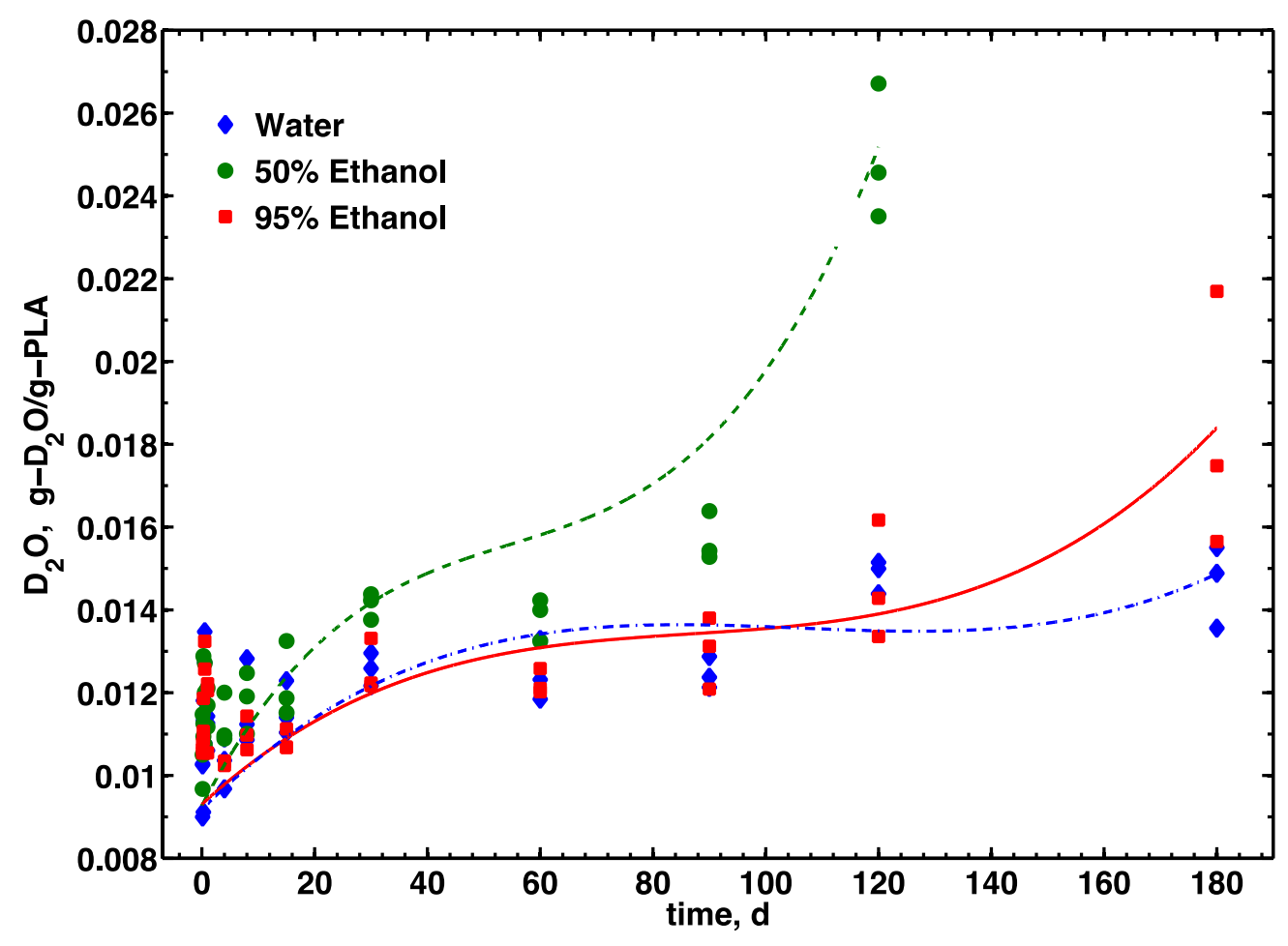

Figure 2. $D_{2} \mathrm{O}$ sorption into PLA films in contact with $D_{2} \mathrm{O}, 50 \%$ ethanol and $95 \%$ ethanol at $40{ }^{\circ} \mathrm{C}$. $y$-axis represents grams of $D_{2} \mathrm{O}$ sorbed divided by grams of PLA remaining in the disk after hydrolysis with $\mathrm{H}_{2} \mathrm{O}$. Trend lines are used as visual aid.

Figure S6, Supporting Information shows immediate ethanol sorption in PLA during hydrolysis. Diffusion coefficients were estimated using Eq. 1, taking into account the swelled thickness of the PLA films at equilibrium (i.e., the initial thickness was $27.94 \mu \mathrm{m}$ and the final estimated thicknesses based on expansion for $50 \%$ and $95 \%$ ethanol were 28.78 and $29.53 \mu \mathrm{m}$, respectively). Table 2 shows the estimated parameters. $D$ for ethanol in disks immersed in $95 \%$ ethanol $\left(5.88 \times 10^{-14} \mathrm{~m}^{2} / \mathrm{s}\right)$ was almost twice the $D$ for ethanol in disks immersed in $50 \%$ 
ethanol $\left(2.55 \times 10^{-14} \mathrm{~m}^{2} / \mathrm{s}\right)$. Also, the amount of ethanol at equilibrium $\left(M_{\infty}\right)$ was $160 \%$ higher in $95 \%$ ethanol than in $50 \%$ ethanol.

Table 2. Diffusion coefficients $(D)$ and amount of ethanol at equilibrium $\left(M_{\infty}\right)$ in PLA films at $40^{\circ} \mathrm{C}$

\begin{tabular}{|c|c|c|}
\hline Solvent & $D \times 10^{14}\left(\mathrm{~m}^{2} / \mathrm{s}\right)$ & $M_{\infty}(g-E t O H / g-P L A)^{\star}$ \\
\hline $50 \%$ Ethanol & $0.64 \pm 0.1^{\mathrm{a}}$ & $0.03 \pm 0.00^{a}$ \\
\hline 95\% Ethanol & $1.47 \pm 0.33^{b}$ & $0.08 \pm 0.00^{b}$ \\
\hline
\end{tabular}

Values with different letter within the same column are statistically different $(\alpha=0.05$

Tukey-Kramer Test)

*Note: grams of ethanol sorbed divided by grams of the PLA disk used for the ${ }^{1} \mathrm{H}-\mathrm{NMR}$ experiments

Experiments were performed using the ${ }^{1} \mathrm{H}-\mathrm{NMR}$ technique to study the relationship between ethanol concentration and polymer expansion when PLA films were exposed to different concentrations of ethanol over $24 \mathrm{~h}$. Figure S7, Supporting Information shows the relationship between \% expansion of PLA and ethanol fraction (volume of ethanol divided by total volume).

The initial first order reaction, $M_{n}=M_{n_{o}} \exp (-k t)$, can be modified to account for the effect of PLA swelling. A model based on the assumption that the expansion of the polymer is due to an increase in void space, not expansion of the chains, predicts that the rate constant is: 
$k=\beta\left[\frac{V_{o}}{V_{d}}+\left(0.06-\frac{V_{o}}{V_{d}}\right) p-0.06 p^{2}\right]$

where $V_{o}$ is the initial void space in the PLA matrix, $V_{d}$ is the volume of the disk, $\beta$ is a constant, and $p$ is the ethanol fraction $(p=0,0.5,0.95)$. This model incorporates the effect of expansion due to ethanol in the rate constant. When $p=0$ (pure water), $k=\beta V_{o} / V_{d}$; and when $p=1$ (no water), $k=0$. The details of how the model was derived are presented in the Supporting Information available online. Fitting $M_{n}=M_{n_{o}} \exp (-k t)$ to the experimental data in Figure 1 with $k$ defined in Eq. 2 gives $\beta=1.05$ and $V_{o} / V_{d}=0.0056$. Using $V_{d}=0.0088 \mathrm{~cm}^{3}$, the initial void space $\left(V_{o}\right)$ in one disk is predicted to be $4.93 \times 10^{-5} \mathrm{~cm}^{3}$. Table 1 shows the rate constants using Eq. 2.

Setting the derivative of $k$ with respect to $p$ in Eq. 2 equal to zero gives the maximum rate of decay in $M_{n}$. This occurs when the volume fraction of ethanol reaches $p \approx 0.45$ (Figure 3 ). At that concentration of ethanol, a competitive balance between swelling and hydrolysis is observed, where the molecules of ethanol swell the polymer and allow the maximum concentration of water into the polymer to start the cleavage of the ester bonds. 


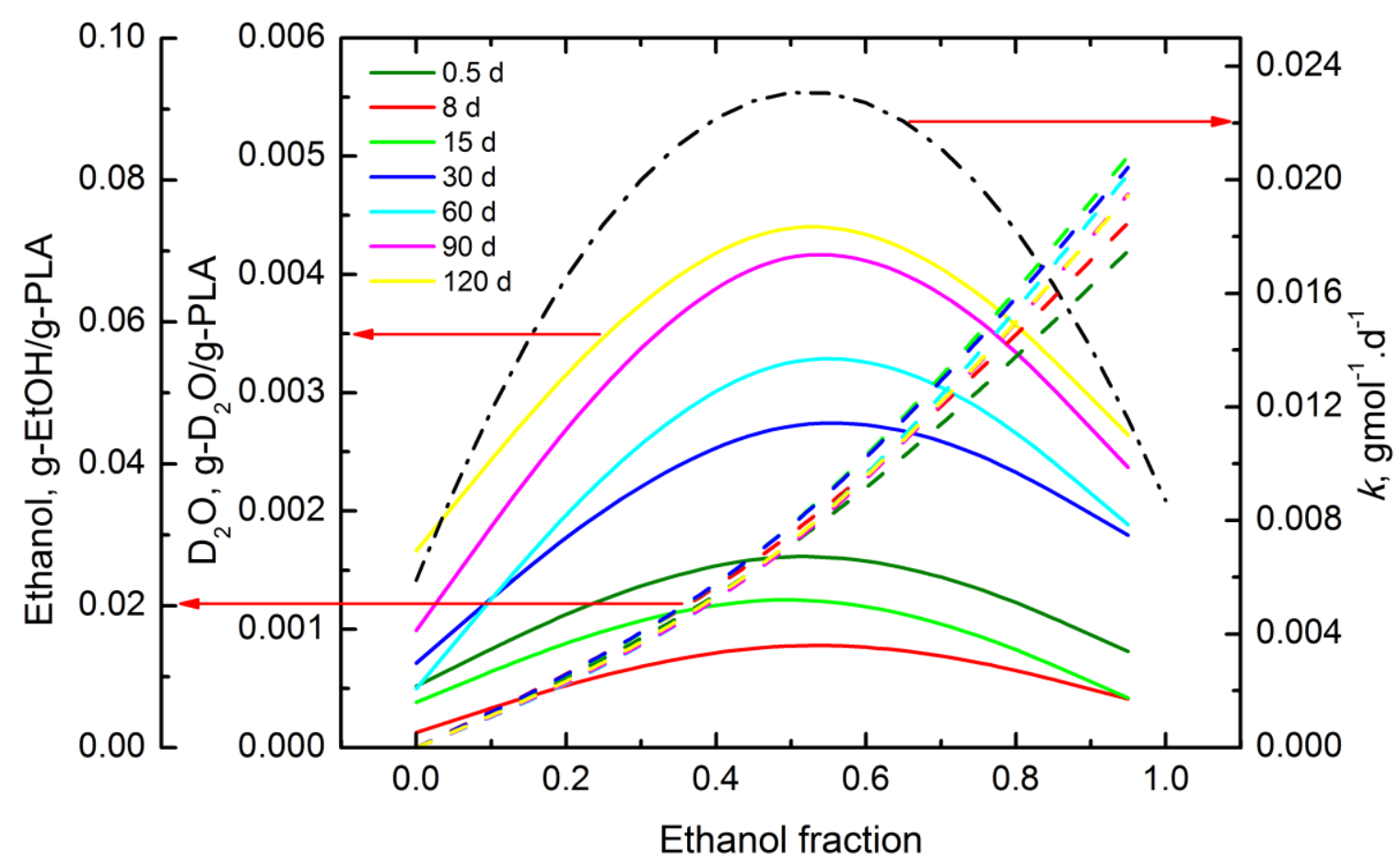

Figure 3. Rate constant for hydrolytic degradation of PLA films fitting first order reaction equation with $k$ from Eq. $2(-\bullet-)$. $D_{2} \mathrm{O}$ sorption (-) and ethanol sorption (--) into PLA at different exposure times versus volume fraction of ethanol in solvent solution at $40^{\circ} \mathrm{C} . \mathrm{D}_{2} \mathrm{O}$ and ethanol sorption lines were obtained from experimental data of PLA immersed in water, 50\% ethanol and 95\% ethanol at different exposure times.

Hydrolytic degradation of PLA occurs in the amorphous regions since they have a larger void volume than the crystalline regions and water can penetrate amorphous regions more readily $[39,45]$. Since hydrolysis reduces the amorphous regions, the degree of crystallinity increases, even though the crystalline regions remain unchanged [25]. On the other hand, exposure of PLA 
to ethanol causes softening in the polymer, resulting in the movement and realignment of polymer chains, which induces crystallinity $[26,46]$. Therefore, it is a combination of structural changes in PLA including swelling and induced crystallinity when exposed to different combined solvents that affects hydrolysis.

Figure 4 shows the change in $T_{g}$ of PLA when immersed in different volume fractions of ethanol at $40^{\circ} \mathrm{C}$. The relationship is linear (Figure 4 insert). The $T_{g}$ of the PLA films before being exposed to hydrolytic degradation was $59.8 \pm 0.5^{\circ} \mathrm{C}$ according to the DSC results. PLA films immersed in $100 \%$ water had a $T_{g}$ of $53^{\circ} \mathrm{C}$, but when PLA was immersed in $50 \%$ and $95 \%$ ethanol, $T_{g}$ was approximately 36 and $20^{\circ} \mathrm{C}$, respectively. This means that the higher the concentration of ethanol in the solution, the lower the $T_{g}$ during solvent transport into PLA, where swelling occurs immediately according to Figure S6, Supporting Information. The plasticization effect of ethanol on PLA allows the movement of the polymer chains, inducing alignment so crystallinity can occur. 


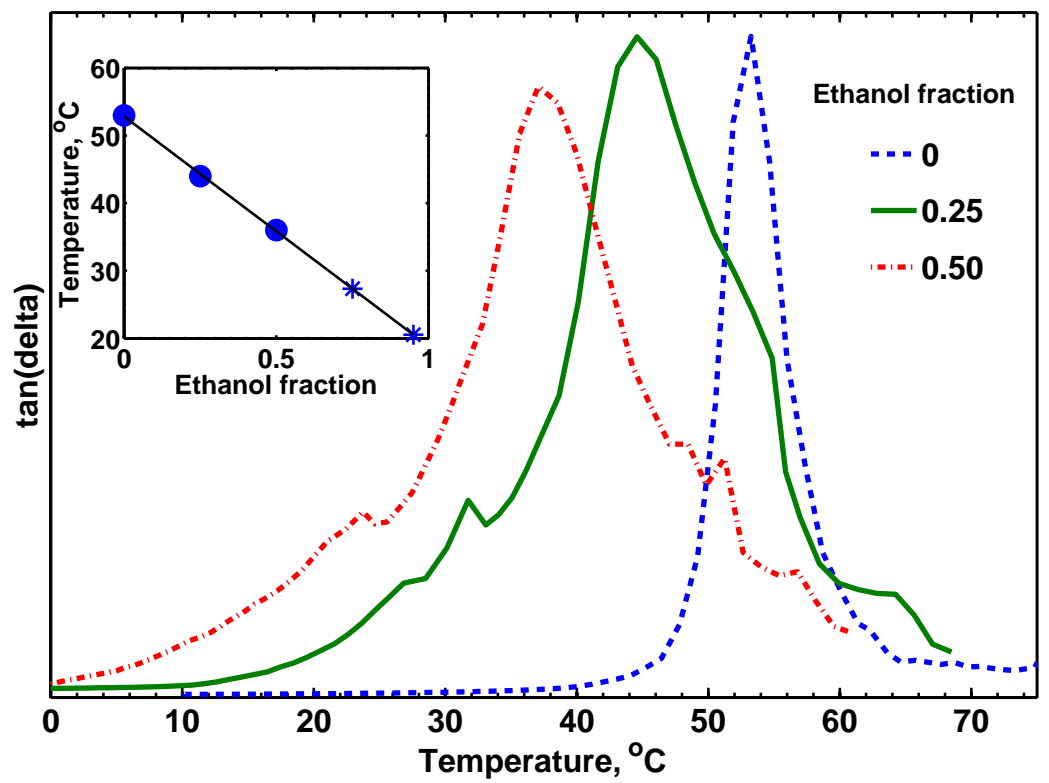

Figure 4. $T_{g}$ of PLA when immersed in different volume fractions of ethanol at $40{ }^{\circ} \mathrm{C}$ from the immersion DMA results. Insert: $T_{g}$ as a function of $p$ where $T_{g}$ values $\left(^{*}\right)$ were estimated when $p>0.5\left(T_{g}=-0.34 p+52.83 ; R^{2}=0.999\right)$.

\section{Crystallinity}

For assessing the crystallinity of PLA during hydrolytic degradation, DSC and XRD techniques were used. DSC was applied to calculate the percent crystallinity and identify changes in $T_{m}, T_{c}$ and $T_{g}$ using DSC thermograms. The identification of the type of crystals formed during PLA hydrolysis was performed by the XRD technique.

Figure 5 shows the percent crystallinity $\left(\% X_{c}\right)$ obtained by the DSC technique during hydrolytic degradation of PLA as a function of time. The crystallinity of samples exposed to water increased from 2.8 to $7.3 \%$ after 6 months of immersion. For PLA films exposed to ethanol solutions, the crystallinity increased 
dramatically. After the first 15 days of immersion, the crystallinity of PLA in 50\% and $95 \%$ ethanol was the same, around $26 \%$. After one month, the $50 \%$ ethanol samples started showing higher crystallinity. The increase on crystallinity during hydrolytic degradation has also been observed in other systems when PLA has been exposed to different environments and $\mathrm{pH}[21,47,48]$.

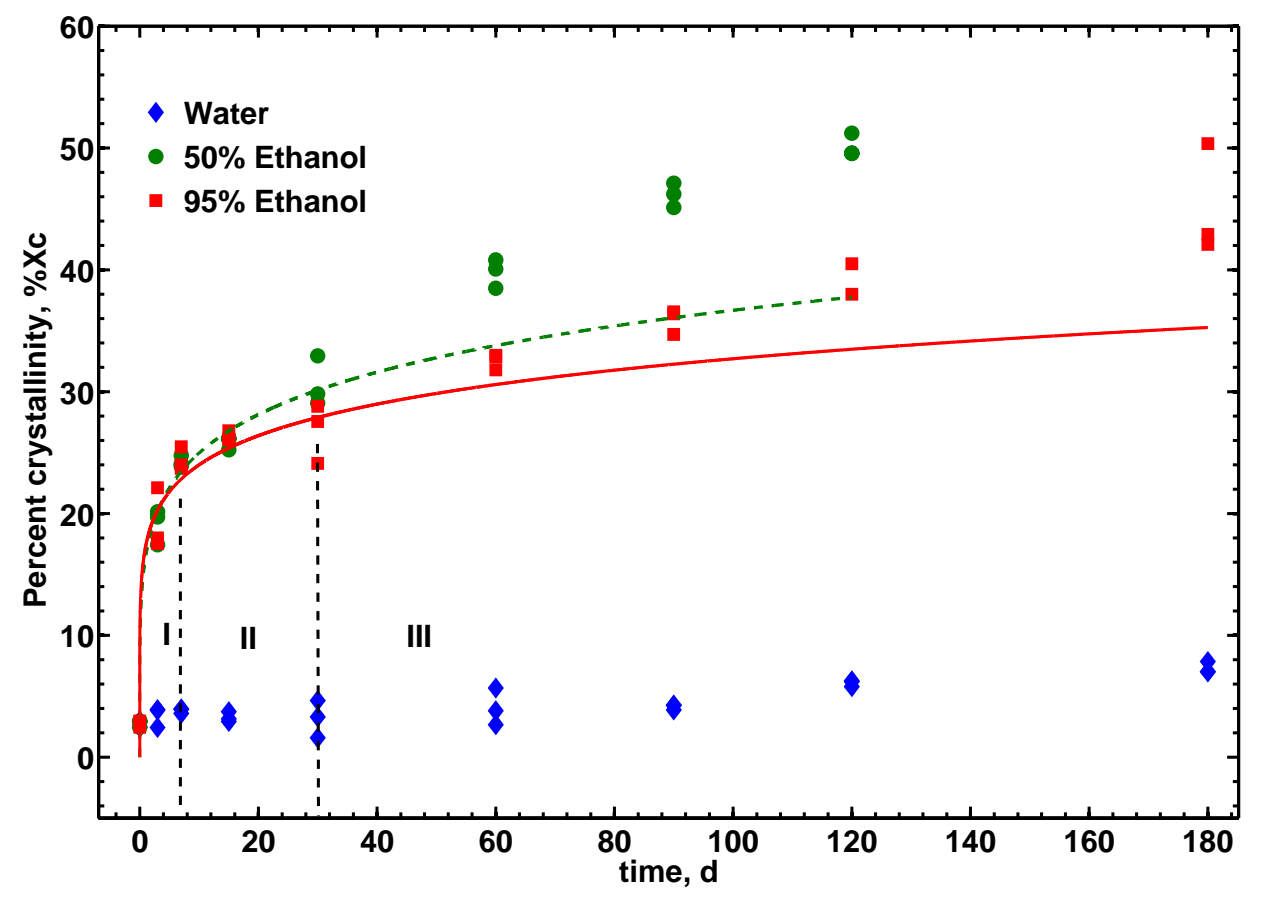

Figure 5. Percent crystallinity during hydrolytic degradation of PLA films immersed in water, $50 \%$ and $95 \%$ ethanol at $40{ }^{\circ} \mathrm{C}$. Trend lines from fitting Avrami equation (Eq. 3). Numbers I, II and III indicate the regions corresponding to the different processes of PLA crystallization. 
The increase in crystallinity can be explained by the depression of $T_{g}$ due to the process of SIC. If $T_{g}$ falls below the test temperature $\left(40^{\circ} \mathrm{C}\right)$, the polymer chains have sufficient mobility and tend to rearrange into a crystalline structure, which is a more stable configuration.[36] According to Ouyang et al., the transport of acetone in poly(ethylene terephthalate) (PET) induces crystallization in three stages [34, 36]. The first stage is the transport of the solvent by diffusion, which is controlled by the concentration gradient. The second stage involves swelling by the solvent and the third stage is secondary crystallization. In the case of PLA, the second stage present in PET is observed in Figure 5 as the region marked with number I due to the dramatic increase in swelling by ethanol, as measured by the change in film thickness. In this region, primary crystallization takes place, where large amounts of crystallites are formed as a result of relaxation of constraints by the release of internal stress, where chains begin to fold and become crystals [34-36]. When the system is in saturation (region II), the crystallization rate is slow and polymer chains can form small crystals dispersed in the amorphous region, corresponding to a secondary crystallization [34, 36]. After 30 days in $95 \%$ ethanol, the crystallinity started to increase (region III). This can be explained by the preferential hydrolysis of the amorphous regions left after secondary crystallization, which increases the net crystalline region as degradation proceeds. For PLA in contact with $50 \%$ ethanol, crystallization due to hydrolysis started after 15 days of exposure, resulting in a higher $\% X_{c}$ than films immersed in $95 \%$ ethanol. The higher $\% X_{c}$ can be explained by the higher 
solubility of water molecules in the amorphous regions, hydrolyzing them faster and therefore increasing the net crystalline regions.

In order to quantify the crystallization kinetics, the Avrami theory $[49,50]$ was applied according to:

$$
X_{c}=1-\exp \left(-K t^{n}\right)
$$

where $X_{c}$ is the relative crystallinity of the polymer, $t$ is time, $K$ the crystallization rate constant, and $n$ is the Avrami exponent. As observed in Figure 5, the Avrami model fits regions I and II well. The deviation from the Avrami equation in region III is due to the hydrolysis of the amorphous region and not to the formation of new crystals. The Avrami kinetic parameters of crystallinity for $50 \%$ ethanol were $K=0.018 \mathrm{~s}^{-1}$ and $n=0.20$, and for $95 \%$ ethanol were $K=0.031 \mathrm{~s}^{-1}$ and $n=0.16$. Generally, the $n$ values reported in the literature are around 2 and 4 [49, 51, 52]. The low values obtained in this study are in accordance with recently reported values by Tsai et al., where PLA was exposed to methanol and ethanol, giving values of 1 and 0.5 , respectively [53]. This is an indication of the uni-dimensional growth of crystals restricted by diffusion of the solvent.

The XRD profiles of PLA films during hydrolytic degradation are shown in Figure 6. When PLA was immersed in pure water, the profiles showed only broad peaks during hydrolysis. These results indicate that PLA immersed in pure water remained amorphous during hydrolysis. No formation of crystals took place, which is in agreement with the $3 \%$ increase in crystallinity during degradation. In contrast, some sharp peaks began to appear after 3 days exposure to $50 \%$ and 
95\% ethanol (Figure 6D and 6E). The diffraction peaks observed in 6 for ethanol solutions correspond to the formation of $\alpha$-form crystals (orthorhombic unit cell with parameters $a=1.06 \mathrm{~nm}, \mathrm{~b}=0.61 \mathrm{~nm}$, and $\mathrm{c}=2.88 \mathrm{~nm}$ ) [54]. In 50\% ethanol, diffraction peaks at $14.8^{\circ}, 16.8^{\circ}, 19.1^{\circ}$ and $22.4^{\circ}$ were observed. In $95 \%$ ethanol, the diffraction peaks were in the same range as in $50 \%$ ethanol. They were $14.8^{\circ}$, $16.7^{\circ}, 19.1^{\circ}$ and $22.2^{\circ}$, corresponding to the $010,110 / 200,100 / 203$ and $102 / 210$ plane reflections, respectively [26, 55-58]. The appearance of crystals in PLA after 3 days exposure to ethanol solutions indicates that SIC took place in the early stages corresponding to primary crystallization (region I). At all times, the diffraction peaks were the same, meaning the same kind of crystals were formed during secondary crystallization (region II) and were present during the entire degradation of the amorphous regions (region III). Zhang, et al. [59] studied the morphology behavior of amorphous PLA during hydrolysis in neutral conditions, and semicrystalline PLA in acid and alkaline environments where $\alpha$-form crystals were mainly formed and remained during the degradation process. 


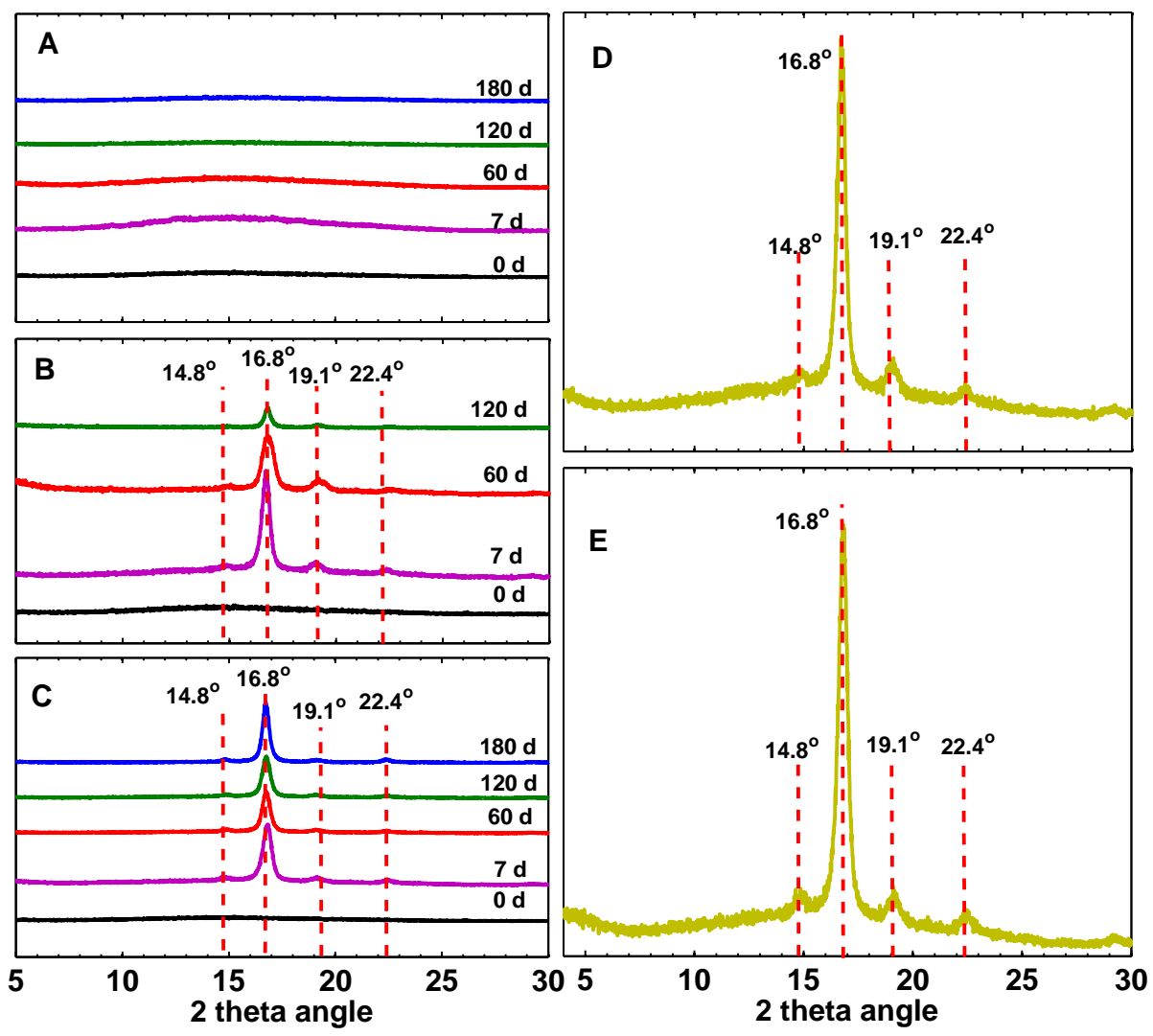

Figure 6. XRD profiles of PLA films during hydrolytic degradation in (A) water, (B) $50 \%$ ethanol, (C) $95 \%$ ethanol and in the $3^{\text {rd }}$ day of immersion in (D) $50 \%$ ethanol and (E) $95 \%$ ethanol at $40^{\circ} \mathrm{C}$. The numbers on each profile indicate days immersed.

Crystallinity results can be correlated with DSC thermograms of PLA before and after being hydrolyzed by water-ethanol solutions for various times (Figure 7). Before exposure, amorphous PLA showed a cold-crystallization temperature peak $\left(T_{c c}\right)$ due to the rearrangement of polymer chains inducing crystallization during the DSC heating process. When PLA was exposed to pure water (Figure 
7A), $T_{c c}$ shifted to a lower temperature. This can be attributed to chain scission and reduction in molecular weight of the PLA matrix, which facilitates nucleation and growth of PLA crystals, improving chain segment mobility $[43,56]$. Another explanation could be the production of locally ordered structures during hydrolysis, promoting the occurrence of cold crystallization at lower temperatures [56]. The double melting peaks could be attributed to the formation of two different crystalline structures formed during the DSC heating process [60, 61]. Some crystals that could be formed during crystallization from melt are the $\alpha$ and $\beta$-forms that have approximately the same energy and therefore the possibility to coexist $[57,62]$. The high $T_{m}$ corresponds to melting of the more stable structure, which is the a-crystal, while the low $T_{m}$ is ascribed to the less perfect crystal that is the $\beta$-form [62]. For PLA exposed to ethanol solutions (Figure 7B and 7C), after the $3^{\text {rd }}$ day, the samples did not show crystallization peaks, meaning that PLA had been crystallized in agreement with the XRD profiles, presenting $\alpha$-form crystals (Figure 6). The a-form crystals are reflected in thermograms displaying only one melting peak over time. However, after 60 days of immersion, a small endothermal peak started to appear and became stronger over time. This phenomenon could be explained by hydrolysis process, which is reflected in the change of the molecular weight distribution (MWD) of PLA (Figure S8, Supporting Information). After 60 days, the MWD of PLA became broader due to polymer chain scission, resulting in shorter polymer chains and the presence of LA oligomers with different $T_{m}$ 's compared to a-form crystals originated by the SIC process (regions I and II, Figure 5). 

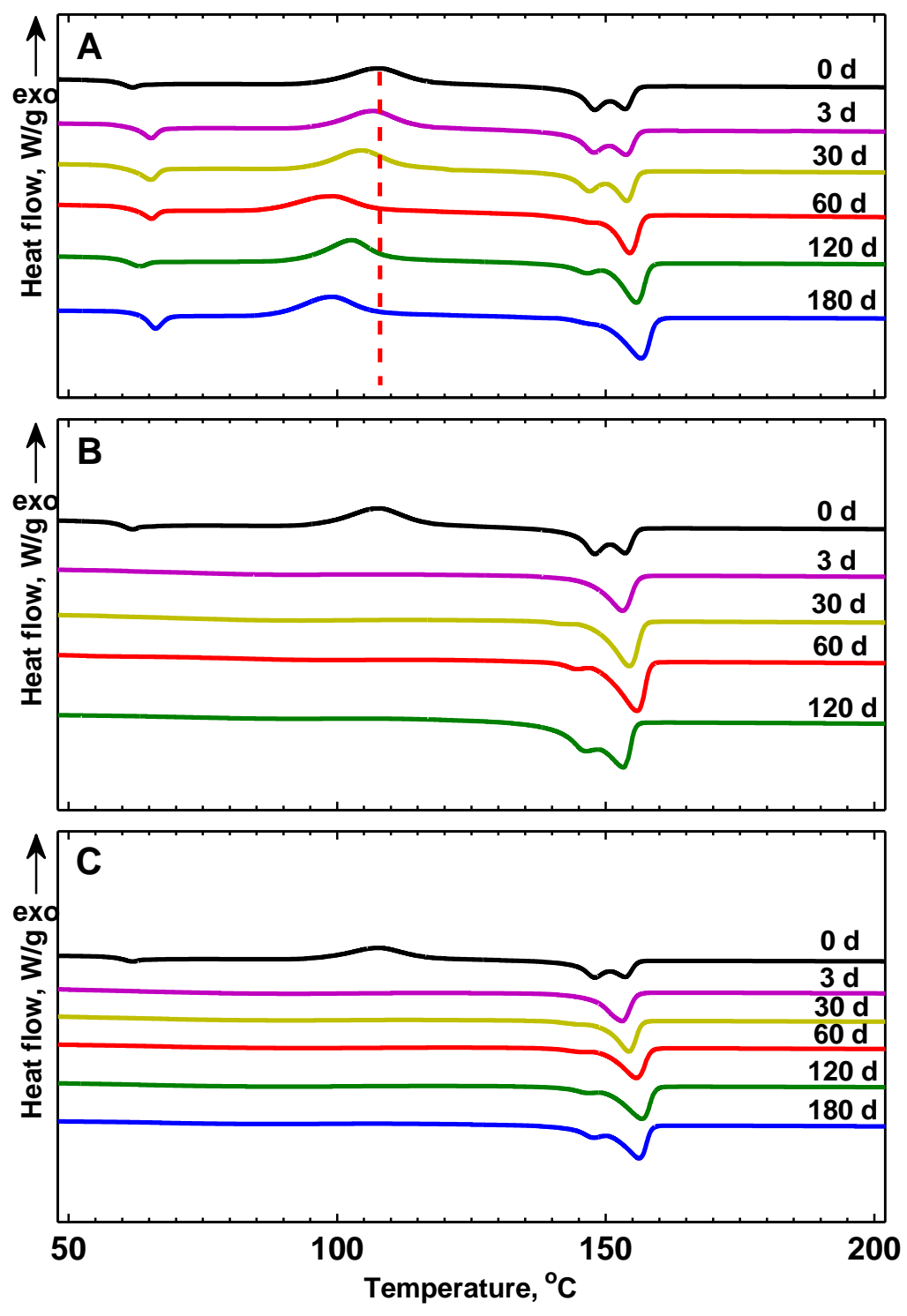

Figure 7. DSC thermograms of PLA film during hydrolytic degradation in (A) water, (B) $50 \%$ ethanol and (C) $95 \%$ ethanol at $40^{\circ} \mathrm{C}$. The numbers on each thermogram indicate days immersed.

\section{Lactic acid release}


During hydrolysis of the amorphous regions of PLA, low molecular weight watersoluble oligomers and monomers are released. Figure 8 shows the release of LA from PLA into water, $50 \%$ and $95 \%$ ethanol at $40{ }^{\circ} \mathrm{C}$. During the first 40 days of exposure, the release of PLA monomers was higher when the polymer was in contact with $50 \%$ ethanol, followed by $95 \%$ ethanol and then by water (Figure 8 insert). After the second month of exposure, the release of LA increased exponentially for samples in contact with $50 \%$ ethanol. At 120 days, the concentration of LA in $50 \%$ ethanol was $700 \mu \mathrm{g} / \mathrm{mL}$, meaning that approximately $30 \%$ of the PLA was hydrolyzed. Not long after that, the film disintegrated. Over the same period, the percentage of PLA hydrolyzed by water and $95 \%$ ethanol was 1.4 and $0.5 \%$, respectively.

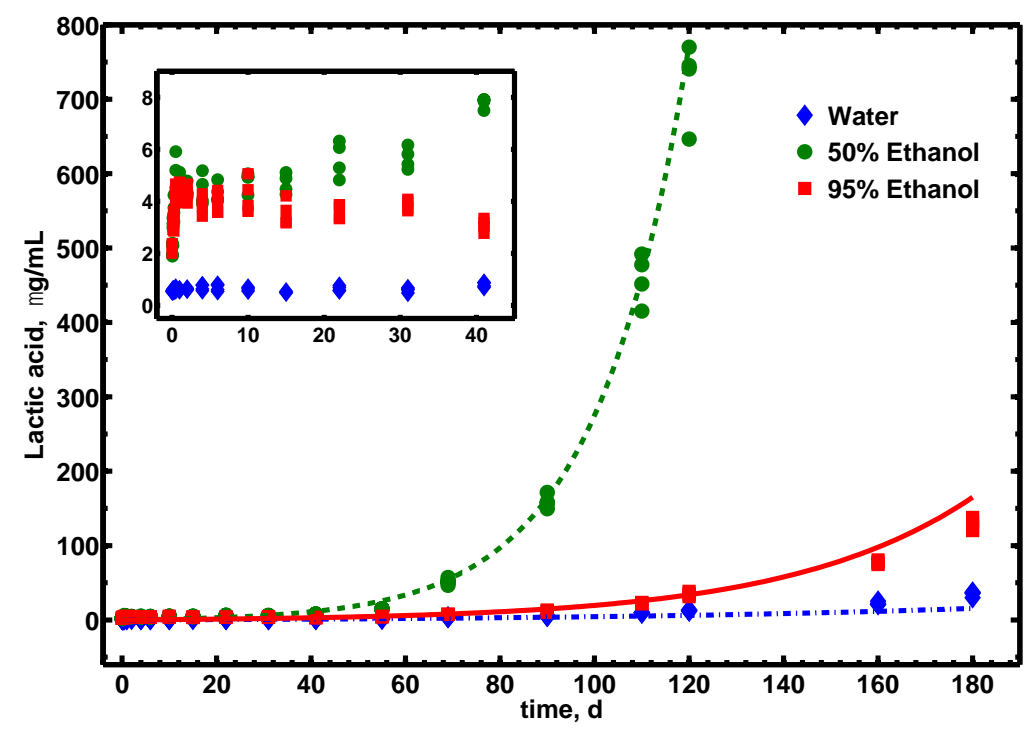

Figure 8. Release of LA during hydrolytic degradation of PLA films in contact with water, $50 \%$ and $95 \%$ ethanol at $40{ }^{\circ} \mathrm{C}$. Fitted lines indicate the prediction of Eq. 4 to each solution. 
The highest release of LA in 50\% ethanol concurs with the fastest reduction in $M_{n}$ (Figure 1), since polymer chains in the amorphous regions are being hydrolyzed faster, as reflected by the increase in $\% X_{c}$ in region III (Figure 5).

A model that predicts $L A$ release is proposed based on the process of chain scission into progressively lower molecular weights, followed by diffusion of LAmers through the PLA matrix, followed by crossing the interface into the fluid, and finally dissolving into LA in the various water-ethanol solutions. The resulting concentration of LA in the solution is described by:

$$
C_{f}=\frac{Q \cdot A}{V_{f}}[\exp (R k t)-1]
$$

where $C_{f}$ is the concentration of LA in the solution, $Q$ and $R$ are constants, $A$ is the disk surface area, $V_{f}$ is fluid volume, $t$ is time, and $k$ is the rate constant in Eq. 2. The development of the model is presented in the Supporting Information. Fitting Eq. 4 to the experimental data gave $Q=0.9 \mu \mathrm{g} / \mathrm{cm}^{2}$ and $R=2.232$. The predicted LA release from PLA hydrolysis immersed in water, 50\% and 95\% ethanol are the curves in Figure 8.

During LA release it is important to consider that the migration rate of molecules within the polymer matrix depends on several factors, including the size of the migrants, density, and the $T_{g}$ of the polymer $[63,64]$. Therefore, changes in $T_{g}$ will affect the release of LA previously discussed since $T_{g}$ will determine the flexibility of polymer chains and the free volume within the matrix. When PLA was exposed to water $\left(T_{g}=53^{\circ} \mathrm{C}\right)$ (Figure 4), the diffusion of LA and LA-mers took 
place in the glassy state because the experiments were conducted at $40^{\circ} \mathrm{C}$. Below $T_{g}$, in the glassy state, the polymer is stiff and therefore less open to diffusion by LA molecules. For PLA immersed in ethanol solutions, diffusion of LA took place above $T_{g}$, in the rubbery state, where the polymer molecules are flexible and open to diffusion $[63,65]$. The higher the ethanol content, the lower the $T_{g}$ and the higher the diffusion rates of LA and LA-mers.

The main migrants from PLA are LA and LA-mers, which are degradation products from the hydrolysis of polymer chains. This study only carried out the quantification of alkali decomposition products based on the conversion of lactide and LA-mers to LA. A theoretical prediction for the rate of diffusion of oligomers up to 5 units was made based on the free volume theory as a function of the $T_{g}$ of the polymer during hydrolysis experiments (Figure S9, Supporting Information). Based on the predictions, the release of LA $(90 \mathrm{~g} / \mathrm{mol})$ is faster when PLA is exposed to $95 \%$ ethanol. These results are not in full agreement with the experimental data since the estimated diffusion coefficient does not take in account hydrolysis of the polymer. It only considers the effect of $T_{g}$.

Predicted values showed that the smaller the molecular weight of the oligomer, the faster the diffusion through PLA. Therefore, the LA quantified during release experiments can be identified as mostly LA released from the PLA matrix and not from the alkali hydrolysis of LA-mers released from PLA in the solution. This finding could be supported by work conducted by Mutsuga, Kawamura and Tanamoto [40] who studied the long-term migration of LA-mers in water at $40^{\circ} \mathrm{C}$. Their results showed that until three months exposure to water, no LA-mers were 
detected. However, by six months, $3.46 \mu \mathrm{g} / \mathrm{cm}^{2}$ of LA-mers up to 13 units were quantified. In our experiment, the initial presence of LA-mers in the PLA films were not detected by MALDI-TOF (data not shown). Therefore, at the early stages the LA quantified during the experiments can be attributed to the hydrolytic degradation of PLA in contact with the water-ethanol solutions and release as mostly LA into solution.

\section{CONCLUSIONS}

The exposure of PLA disks to different water-ethanol solutions led to the hydrolytic degradation of the polymer with concurrent SIC. Hydrolysis was accelerated by the immersion of PLA in 50\% ethanol, which showed a faster reduction in $M_{n}$ than in $95 \%$ ethanol and pure water. Hydrolysis is related to the amount of water molecules available to start chain scission, so NMR techniques were applied to study water sorption in PLA. Higher sorption of $D_{2} O$ was found when PLA was exposed to $50 \%$ ethanol, explaining the faster hydrolysis. A new model was proposed to explain the rate of hydrolysis, accounting for the effect of PLA swelling due to ethanol sorption. The rate of degradation for $50 \%$ ethanol was $0.0230 \mathrm{gmol}^{-1} \mathrm{~d}^{-1}$. This was the maximum rate of decay in $M_{n}$, meaning that $50 \%$ concentration provides the optimal competitive balance between swelling and hydrolysis. During PLA hydrolysis the $\% X_{c}$ increased, indicating that SIC occurred in PLA when exposed to $50 \%$ and $95 \%$ ethanol. In the crystallization process of PLA, three different regions were identified. Regions I and II were due 
to SIC by ethanol. The Avrami equation was found to describe the crystallization process well. Region III was due to hydrolysis of the amorphous regions. XRD studies showed the formation of $\alpha$-crystal during SIC. LA release was studied as an indication of hydrolysis of PLA. PLA immersed in $50 \%$ ethanol showed the highest release of $L A$, which is in accordance with the fastest decay in $M_{n}$ by hydrolysis. A model was proposed to predict LA release during hydrolysis when PLA is exposed to different ethanol-water solutions.

\section{ACKNOWLEDGMENTS}

The authors thank Olivier Vitrac for assistance with estimating theoretical LA diffusion coefficients. I-F, F., thanks the Mexican National Council for Science and Technology (CONACYT), the Mexican Secretariat of Public Education (SEP) and the Government of Mexico for providing financial support through a Ph.D. fellowship. RA thanks partial support of the USDA National Institute of Food and Agriculture and Michigan AgBioResearch, Hatch project R. Auras.

\section{REFERENCES}

[1] R. Auras, B. Harte, S. Selke, An overview of polylactides as packaging materials, Macromol. Biosci., 4 (2004) 835-864. 
[2] E.T. Vink, S. Davies, Life Cycle Inventory and Impact Assessment Data for 2014 Ingeo $^{\text {TM }}$ Polylactide Production, Ind. Biotechnol., 11 (2015) 167-180.

[3] N. Bleach, K. Tanner, M. Kellomäki, P. Törmälä, Effect of filler type on the mechanical properties of self-reinforced polylactide-calcium phosphate composites, J. Mater. Sci. Mater. Med., 12 (2001) 911-915.

[4] Y. Ikada, H. Tsuji, Biodegradable polyesters for medical and ecological applications, Macromol. Rapid Commun., 21 (2000) 117-132.

[5] J.-Y. Park, I.-H. Lee, Controlled release of ketoprofen from electrospun porous polylactic acid (PLA) nanofibers, J. Polym. Res., 18 (2011) 1287-1291. [6] K.E. Uhrich, S.M. Cannizzaro, R.S. Langer, K.M. Shakesheff, Polymeric systems for controlled drug release, Chem. Rev., 99 (1999) 3181-3198.

[7] Y.-N. Chang, R.E. Mueller, E.L. Iannotti, Use of low MW polylactic acid and lactide to stimulate growth and yield of soybeans, Plant Growth Regul., 19 (1996) 223-232.

[8] R.G. Sinclair, Slow-release pesticide system. Polymers of lactic and glycolic acids as ecologically beneficial, cost-effective encapsulating materials, Environ. Sci. Technol., 7 (1973) 955-956.

[9] K.M. Nampoothiri, N.R. Nair, R.P. John, An overview of the recent developments in polylactide (PLA) research, Bioresour. Technol., 101 (2010) 8493-8501. 
[10] D.G. Hayes, S. Dharmalingam, L.C. Wadsworth, K.K. Leonas, C. Miles, D. Inglis, Biodegradable agricultural mulches derived from biopolymers, in: C.S. Kishan Khemani (Ed.) Degradable polymers and materials: Principles and practice, American Chemical Society, Washington, DC, 2012, pp. 201-223.

[11] NatureWorks, NatureWorks PLA helps Delhaize extend environmentallyfriendly packaging to Belgian costumers, in, 2005.

[12] NatureWorks, Pacific Pre-cut enhances the freshness of its brand with NatureWorks PLA packaging for fresh-packed salads, in, 2005.

[13] NaureWorks, SPAR Austria enhances freshness of produce with NatureWorks PLA, in, 2005.

[14] C.G. Pitt, M.M. Gratzl, A.R. Jeffcoat, R. Zweidinger, A. Schindler, Sustained drug delivery systems II: Factors affecting release rates from poly $(\varepsilon-$ caprolactone) and related biodegradable polyesters, J. Pharm. Sci., 68 (1979) 1534-1538.

[15] M.-K. Lai, R.-C. Tsiang, Microencapsulation of acetaminophen into poly (Llactide) by three different emulsion solvent-evaporation methods, J. Microencapsulation, 22 (2005) 261-274.

[16] L. Zhang, C. Long, J. Pan, Y. Qian, A Dissolution - Diffusion Model and Quantitative Analysis of Drug Controlled Release from Biodegradable Polymer Microspheres, Can. J. Chem. Eng, 84 (2006) 558-566. 
[17] C. Gualandi, M. Govoni, L. Foroni, S. Valente, M. Bianchi, E. Giordano, G. Pasquinelli, F. Biscarini, M.L. Focarete, Ethanol disinfection affects physical properties and cell response of electrospun poly (I-lactic acid) scaffolds, Eur. Polym. J., 48 (2012) 2008-2018.

[18] Z. Pan, J. Ding, Poly (lactide-co-glycolide) porous scaffolds for tissue engineering and regenerative medicine, Interface Focus, 2 (2012) 366-377.

[19] M. Ahmed, G. Punshon, A. Darbyshire, A.M. Seifalian, Effects of sterilization treatments on bulk and surface properties of nanocomposite biomaterials, J. Biomed. Mater. Res. Part B Appl. Biomater, (2013).

[20] C. Xiang, A.G. Taylor, J.P. Hinestroza, M.W. Frey, Controlled release of nonionic compounds from poly (lactic acid)/cellulose nanocrystal nanocomposite fibers, J. Appl. Polym. Sci., 127 (2013) 79-86.

[21] M.K. Mitchell, D.E. Hirt, Degradation of PLA fibers at elevated temperature and humidity, Polym. Eng. Sci., (2014).

[22] S. De Jong, E.R. Arias, D. Rijkers, C. Van Nostrum, J. Kettenes-Van den Bosch, W. Hennink, New insights into the hydrolytic degradation of poly (lactic acid): participation of the alcohol terminus, Polymer, 42 (2001) 2795-2802.

[23] H. Tsuji, K. Sumida, Poly (L - lactide): V. Effects of storage in swelling solvents on physical properties and structure of poly ( $\mathrm{L}$ - lactide), J. Appl. Polym. Sci., 79 (2001) 1582-1589. 
[24] R.A. Auras, S.P. Singh, J.J. Singh, Evaluation of oriented poly (lactide) polymers vs. existing PET and oriented PS for fresh food service containers, Packag. Technol. Sci., 18 (2005) 207-216.

[25] H. Tsuji, Hydrolytic Degradation, in: R. Auras, L.T. Lim, S. Selke, H. Tsuji (Eds.) Poly(lactic acid). Synthesis, Structures, Properties, Processing, and Applications, John Wiley \& Sons, Inc., New Jersey, 2010, pp. 345-381.

[26] S. Sato, D. Gondo, T. Wada, S. Kanehashi, K. Nagai, Effects of various liquid organic solvents on solvent - induced crystallization of amorphous poly (lactic acid) film, J. Appl. Polym. Sci., 129 (2013) 1607-1617.

[27] J. Gao, L. Duan, G. Yang, Q. Zhang, M. Yang, Q. Fu, Manipulating poly (lactic acid) surface morphology by solvent-induced crystallization, Appl. Surf. Sci., 261 (2012) 528-535.

[28] N. Wu, S. Lang, H. Zhang, M. Ding, J. Zhang, Solvent-Induced Crystallization Behaviors of PLLA Ultrathin Films Investigated by RAIR Spectroscopy and AFM Measurements, J. Phys. Chem. B, 118 (2014) $12652-$ 12659.

[29] S. Lee, Fourteen-year-old aging study of the effect of thickness on methanol transport in crosslinked poly (methyl methacrylate), J. Mater. Res., 11 (1996) 2403-2405. 
[30] S.M. Aharoni, N.S. Murthy, Effects of Solvent-induced Crystallization on the Amorphous Phase of Polycarbonate of bisphenol A), Int. J. Polymer. Mater., 42 (1998) 275-283.

[31] K. Tashiro, Y. Ueno, A. Yoshioka, M. Kobayashi, Molecular mechanism of solvent-induced crystallization of syndiotactic polystyrene glass. 1. Time-resolved measurements of infrared/Raman spectra and X-ray diffraction, Macromolecules, 34 (2001) 310-315.

[32] K. Tashiro, A. Yoshioka, Molecular mechanism of solvent-induced crystallization of syndiotactic polystyrene glass. 2. Detection of enhanced motion of the amorphous chains in the induction period of crystallization, Macromolecules, 35 (2002) 410-414.

[33] A. Yoshioka, K. Tashiro, Thermally-and solvent-induced crystallization kinetics of syndiotactic polystyrene viewed from time-resolved measurements of infrared spectra at the various temperatures (1) estimation of glass transition temperature shifted by solvent absorption, Polymer, 44 (2003) 6681-6688.

[34] W.-H. Lee, H. Ouyang, M.-C. Shih, M.-H. Wu, Kinetics of solvent-induced crystallization of poly (ethylene terephthalate) at the final stage, J. Polym. Res., 10 (2003) 133-137.

[35] H. Ouyang, W.-H. Lee, W. Ouyang, S.-T. Shiue, T.-M. Wu, Solvent-induced crystallization in poly (ethylene terephthalate) during mass transport: mechanism and boundary condition, Macromolecules, 37 (2004) 7719-7723. 
[36] H. Ouyang, W.-H. Lee, M.-C. Shih, Three stages of crystallization in poly (ethylene terephthalate) during mass transport, Macromolecules, 35 (2002) 8428-8432.

[37] ASTM, Standard 47544-11. Standard test method for two-sided liquid extraction of plastic materials using FDA migration cell. , ASTM International, West Conshohocken, PA, 2011.

[38] J. Crank, The Mathematics of Diffusion, 2nd ed., Oxford Science Publications, Oxford, 1975.

[39] E. Fischer, H.J. Sterzel, G. Wegner, Investigation of the structure of solution grown crystals of lactide copolymers by means of chemical reactions, Kolloid Z. Z. Polym., 251 (1973) 980-990.

[40] M. Mutsuga, Y. Kawamura, K. Tanamoto, Migration of lactic acid, lactide and oligomers from polylactide food-contact materials, Food Addit. Contam., 25 (2008) 1283-1290.

[41] L. Di Maio, P. Scarfato, M.R. Milana, R. Feliciani, M. Denaro, G. Padula, L. Incarnato, Bionanocomposite polylactic acid/organoclay films: functional properties and measurement of total and lactic acid specific migration, Packag. Technol. Sci., 27 (2014) 535-547.

[42] N. Gulati, Use of QMC technology for measuring barrier properties of biodegradable packaging material, in: School of Packaging, Michigan State University, Michigan, 2008. 
[43] W. Tham, B. Poh, Z.M. Ishak, W. Chow, Water absorption kinetics and hygrothermal aging of poly (lactic acid) containing halloysite nanoclay and maleated rubber, J. Polym. Environ., (2015) 1-9.

[44] G.L. Siparsky, K.J. Voorhees, J.R. Dorgan, K. Schilling, Water transport in polylactic acid (PLA), PLA/polycaprolactone copolymers, and PLA/polyethylene glycol blends, J. Environ. Polym. Degr., 5 (1997) 125-136.

[45] C. Chu, Hydrolytic degradation of polyglycolic acid: tensile strength and crystallinity study, J. Appl. Polym. Sci., 26 (1981) 1727-1734.

[46] C.G. Pitt, G. Zhong-wei, Modification of the rates of chain cleavage of poly ( $\epsilon$-caprolactone) and related polyesters in the solid state, J. Controlled Release, 4 (1987) 283-292.

[47] X. Yuan, A.F. Mak, K. Yao, In vitro degradation of poly ( $L$ - lactic acid) fibers in phosphate buffered saline, J. Appl. Polym. Sci., 85 (2002) 936-943.

[48] H. Tsuji, Y. Ikada, Properties and morphology of poly (L - lactide). II. Hydrolysis in alkaline solution, J. Polym. Sci., Part A: Polym. Chem., 36 (1998) 59-66.

[49] J. Cai, M. Liu, L. Wang, K. Yao, S. Li, H. Xiong, Isothermal crystallization kinetics of thermoplastic starch/poly (lactic acid) composites, Carbohydr. Polym., 86 (2011) 941-947. 
[50] A. Kalkar, V. Deshpande, M. Kulkarni, Isothermal crystallization kinetics of poly (phenylene sulfide)/TLCP composites, Polym. Eng. Sci., 49 (2009) 397-417.

[51] G. Papageorgiou, D. Achilias, S. Nanaki, T. Beslikas, D. Bikiaris, PLA nanocomposites: effect of filler type on non-isothermal crystallization, Thermochim. Acta, 511 (2010) 129-139.

[52] T. Ke, X. Sun, Melting behavior and crystallization kinetics of starch and poly (lactic acid) composites, J. Appl. Polym. Sci., 89 (2003) 1203-1210.

[53] W.-C. Tsai, M. Hedenqvist, Å. Laiback, H. Melin, M. Ngo, M. Trollsås, U. Gedde, Physical changes and sorption/desorption behaviour of amorphous and semi-crystalline PLLA exposed to water, methanol and ethanol, Eur. Polym. J., 76 (2016) 278-293.

[54] S. Sasaki, T. Asakura, Helix distortion and crystal structure of the $\alpha$-form of poly (I-lactide), Macromolecules, 36 (2003) 8385-8390.

[55] H. Marubayashi, S. Asai, M. Sumita, Complex crystal formation of poly (Ilactide) with solvent molecules, Macromolecules, 45 (2012) 1384-1397.

[56] H.-m. Chen, Y. Shen, J.-h. Yang, T. Huang, N. Zhang, Y. Wang, Z.-w. Zhou, Molecular ordering and $\alpha^{\prime}$-form formation of poly (I-lactide) during the hydrolytic degradation, Polymer, 54 (2013) 6644-6653.

[57] M. Yasuniwa, S. Tsubakihara, K. lura, Y. Ono, Y. Dan, K. Takahashi, Crystallization behavior of poly (L-lactic acid), Polymer, 47 (2006) 7554-7563. 
[58] H. Zhou, T.B. Green, Y.L. Joo, The thermal effects on electrospinning of polylactic acid melts, Polymer, 47 (2006) 7497-7505.

[59] X. Zhang, M. Espiritu, A. Bilyk, L. Kurniawan, Morphological behaviour of poly (lactic acid) during hydrolytic degradation, Polym. Degrad. Stab., 93 (2008) 1964-1970.

[60] K. Fukushima, C. Abbate, D. Tabuani, M. Gennari, G. Camino, Biodegradation of poly (lactic acid) and its nanocomposites, Polym. Degrad. Stab., 94 (2009) 1646-1655.

[61] K. Fukushima, D. Tabuani, G. Camino, Nanocomposites of PLA and PCL based on montmorillonite and sepiolite, Mater. Sci. Eng., C, 29 (2009) 1433-1441.

[62] W. Hoogsteen, A. Postema, A. Pennings, G. Ten Brinke, P. Zugenmaier, Crystal structure, conformation and morphology of solution-spun poly (L-lactide) fibers, Macromolecules, 23 (1990) 634-642.

[63] E. Helmroth, R. Rijk, M. Dekker, W. Jongen, Predictive modelling of migration from packaging materials into food products for regulatory purposes, Trends Food Sci. Tech., 13 (2002) 102-109.

[64] S.T. Ju, J.L. Duda, J.S. Vrentas, Influence of temperature on the diffusion of solvents in polymers above the glass transition temperature, Ind. Eng. Chem. Prod. Res. Dev., 20 (1981) 330-335. 
[65] J. Vrentas, C. Vrentas, Fickian diffusion in glassy polymer - solvent systems, J. Polym. Sci., Part B: Polym. Phys., 30 (1992) 1005-1011. 
